\title{
Trace element composition of garnet kelyphites in xenoliths from Udachnaya as evidence of their origin
}

\author{
Z.V. Spetsius ${ }^{1}$ and W.L.Griffin ${ }^{2,3}$ \\ 1. Institute of Diamond Industry, Mirny, Yakutia, Russia \\ 2. GEMOC National Key Centre, Macquarie University, NSW 2109, Australia \\ 3. CSIRO Exploration and Mining, P.O. Box 136, N. Ryde, NSW 2113, Australia
}

Trace elements have been determined by ICP-MS in garnet and their kelyphitic rims in garnet peridotites from the Udachnaya kimberlite pipe. Comparison of these data with the trace element patterns of kimberlites shows significant differences in REE distribution and suggest a deep origin for the kelyphitization.

\section{Introduction}

Kelyphitic rims are widespread on grains of garnet in kimberlites and mantle xenoliths from kimberlite pipes in Yakutia and South Africa. Usually they consist of a mixture of secondary minerals such as phlogopite, spinel, clino- and orthopyroxene. Some rims are complicated especially on grains of garnets in kimberlites and consist of two or more zones with different composition. In xenoliths of garnet peridotite from Udachnaya pipe, garnets are mantled by coronas of phlogopite, spinel and secondary pyroxenes. While major and trace element zoning in garnet are explained as a result of metasomatic processes at depth (Griffin et al., 1989), the formation of kelyphites around garnets usually is linked to interaction between garnet and ascending kimberlitic magma. To test this idea, trace element analysis has been undertaken on chemically homogeneous garnet grains with sharp kelyphitic rims more than 300-500 $\mu \mathrm{m}$ thick, in two peridotite xenoliths from Udachnaya kimberlite pipe (Spetsius, 1995): U-140/78 (sheared Gt lherzolite) and U-2292 (mosaic-porphyroclastic Gt - harzburgite). Trace elements were measured by laser-ablation ICP-MS at Maquarie University, with NIST 610 glass as external standard and $\mathrm{Ca}$ as internal standard; pit diameters were $40 \mu \mathrm{m}$.

\section{Results and discussion}

Observations in thin-section show no notable interaction between peridotite xenoliths and kimberlite melt. There are no obvious relationship of the thickness of kelyphitic rims with the size of xenoliths or any increase in thickness in the outer parts of samples. In areas where kimberlite is in contact with the minerals of the outer zone, there is a sharp border between garnet grains and kimberlite minerals. As was shown by Vishnevsky (1991) kelyphitic rims on garnet in xenoliths usually represent a mixture of minerals: $\mathrm{Ol}+\mathrm{Sp}+\mathrm{Cpx} \pm \mathrm{Opx} \pm \mathrm{Phl}$. The same paragenesis is observed in our samples. Significant variations between core and rim in major and trace element composition were not observed in tested garnets from all samples. This suggests complete reequilibration during ductile shearing in the mantle.

The REE compositions of the investigated garnets are similar, but 2292 shows enrichment in MREE, while 140 does not (Fig. 1). The kelyphites in the two samples have trace-element patterns different from one another, but essentially identical to their host garnet, except for enrichment in Sr. The REE patterns are significantly flatter than would be expected from equilibration with kimberlite magma (Hoal et al., 1994). The very high $\mathrm{Sr}$ contents probably reside in secondary clinopyroxene, and locally high $\mathrm{Ba}$ (not shown) in secondary phlogopite. Otherwise, 
the similarity between garnet and kelyphite analyses suggests that kelyphitization has not involved extensive exchange with a metasomatic medium.

Two models can be proposed to explain the petrographic features and trace element patterns of the kelyphites.

1. PT-estimates for the kelyphite overprint, using secondary minerals within coronas (Vishnevsky, 1991; Franz et al., 1995) indicate temperatures of $1100-1250{ }^{\circ} \mathrm{C}$ and pressures of about $20 \mathrm{~kb}$. These data suggest that kelyphitisation has occurred under upper mantle conditions. According to Franz et al. (1995), in xenoliths from the Gibeon kimberlite these metasomatic processes have occurred within a magma chamber located close to the boundary between upper mantle and lower crust.

2. We propose an alternative explanation based in particular on trace element data and some petrographic evidence. We emphasise that the trace element patterns of the kelyphite are not related to the kimberlitic magma, but resemble those of the garnet being replaced (Fig. 1), with addition of $\mathrm{Sr}, \mathrm{K}$ and probably $\mathrm{Ba}$; HFSE such as $\mathrm{Zr}, \mathrm{Hf}, \mathrm{Ti}$ and $\mathrm{Nb}$, and the REE, were not affected. Experimental trace element partitioning data (Brenan et al., 1995) indicate that at high pressure many of these trace elements do not partition into hydrous fluids to the same degree as into carbonatitic and silicate melts. This suggests that kelyphitization of garnet was not a result of interaction with silicate melt or carbonate-rich fluid, and that hydrous fluids play a more important role in formation of kelyphite on garnets (at this stage of mantle metasomatism). The fine grain size of kelyphite implies that the metasomatic processes which caused replacement of garnet were short-lived and probably were active not long before eruption of kimberlites, but the eruption process is very rapid. We therefore suggest that kelyphite formed in response to the infiltration of hydrous fluids, prior to eruption. The source and precise nature of the metasomatic fluids remains problematic, but we speculate that they were related to a protokimberlitic magma.

\section{Conclusion}

Garnet peridotite xenoliths from kimberlite pipe Udachnaya provide spectacular evidence of the metasomatic kelyphitization of garnets. Petrographic features, mineral associations and trace element patterns in kelyphites and garnet relicts suggest that these processes took place under upper mantle conditions in the presence of water-rich fluids. Most probably, this stage of metasomatism was caused by protokimberlitic fluids shortly before eruption of kimberlites.

\section{References}

Brenan, J.M., Shaw, H.F., Ryerson, F.J., and Phinney, D.L., 1995, Mineral-aqueous fluid partitioning of trace elements at $900^{\circ} \mathrm{C}$ and $2 \mathrm{Gpa}$ : constraints on the trace element chemistry of mantle and deep crustal fluids, Geochim.Cosmochim Acta 55, 2203-2214.

Franz, L., Brey, G.P., and Okrusch M., 1995. Metasomatic reequilibration of mantle xenoliths from the Gibeon kimberlite province (Namibia), Ext. Abstr., Sixth Intern. Kimberlite Conf., 169-171.

Hoal, K.E.O., Hoal, B.G., Erlank, A.J., Shimizu, N., 1994, Metasomatism in the mantle lithosphere recorded by rare earth elements in garnets, Earth Planet. Sci. Lett., 126, 303-313.

Spetsius, Z. V, 1995, Occurrence of diamond in the mantle: a case study from the Siberian Platform, J. Geochem. Expl or., 53, p. 25-39.

Vischnevsky, A.A., 1991, Kelyphites on garnets in mantle xenoliths and kimberlites: compositions, genesis, petrological implications, Ext. Abst., Fifth Intern. Kimb. Conf., 571-572. 


\section{Udachnaya Garnets and Kelyphites}

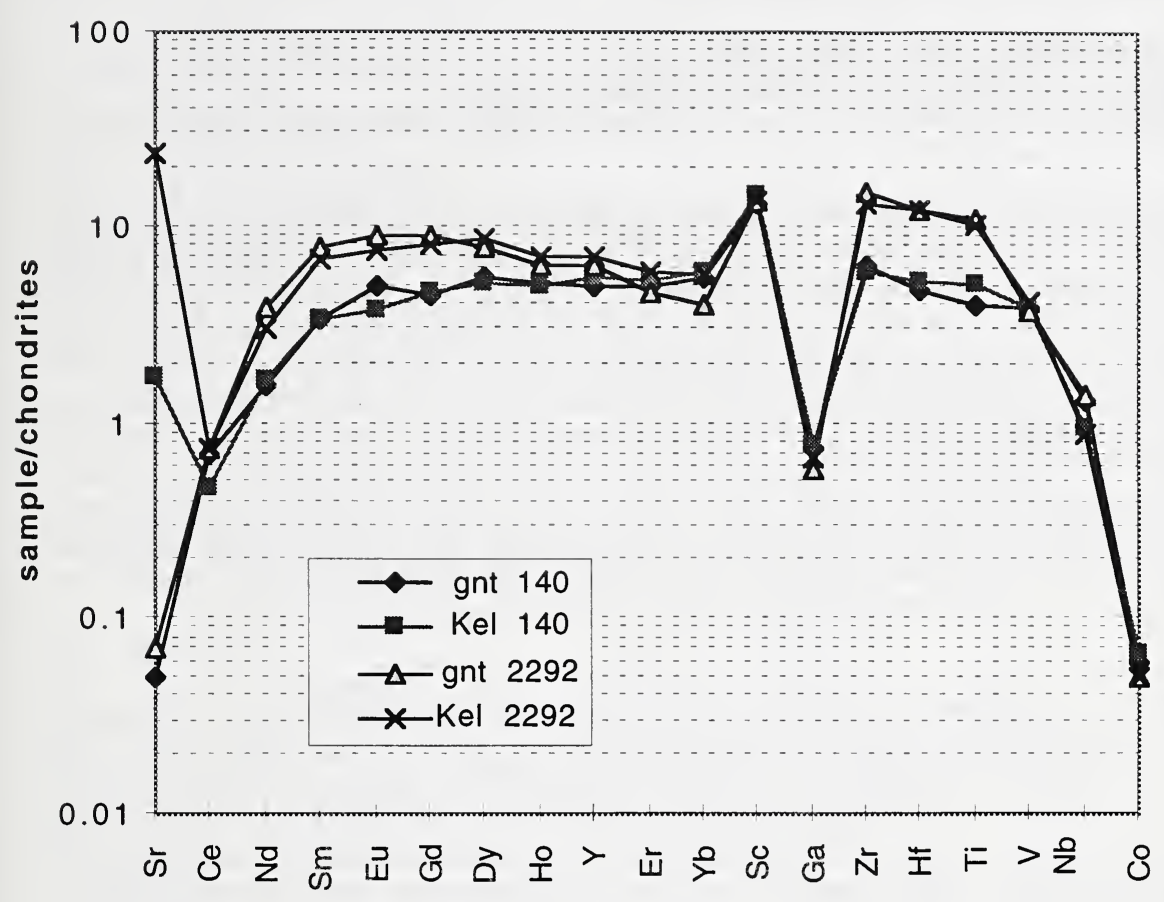

Figure 1. Chondrite-normalised trace element patterns for garnets and kelyphites in sheared garnet peridotite xenoliths U140/78 and U-2292 from the Udachnaya kimberlite, Yakutia. 